\title{
Genetic Structure of Sympatric Sexually and Parthenogenetically Reproducing Population of Chara canescens (Charophyta)
}

\author{
Ralf Schaible, ${ }^{1,2}$ Ingo Bergmann, ${ }^{1,3}$ and Hendrik Schubert ${ }^{1}$ \\ ${ }^{1}$ Department of Aquatic Ecology, Institute of Biosciences, University of Rostock, Albert-Einstein Straße 3, 18051 Rostock, Germany \\ ${ }^{2}$ Laboratory of Evolutionary Biodemography, Max Planck Institute for Demographic Research, Konrad Zuse Straße 1, \\ 18057 Rostock, Germany \\ ${ }^{3}$ Department of Bioengineering, Leibniz-Institute for Agricultural Engineering Potsdam-Bornim, Max-Eyth-Allee 100, \\ 14469 Potsdam, Germany
}

Correspondence should be addressed to Ralf Schaible, ralf.schaible@uni-rostock.de

Received 31 January 2011; Accepted 17 March 2011

Academic Editor: W. Shi

Copyright (c) 2011 Ralf Schaible et al. This is an open access article distributed under the Creative Commons Attribution License, which permits unrestricted use, distribution, and reproduction in any medium, provided the original work is properly cited.

Individuals that reproduce parthenogenetically do not have to produce males and can therefore produce twice as many female offspring. With this twofold reproduction advantage of asexual reproduction, the question of how sex persists in the short term remains unresolved. In the dioecious charophyte Chara canescens, both parthenogenetically reproducing females and sexually reproducing females and males occur sympatrically at only one site in Europe: Neusiedler See-Seewinkel (Austria). By means of four nuclear species-specific microsatellite loci, we examined the interaction between coexisting sexuals and parthenogens by analysing the population structure and gene flow between both reproduction systems. Using a Bayesian assignment method, we found that the sites encompassed two genetically distinct clusters of individuals. The first cluster included genotypes of sexual individuals, which are genetically distinct from a second cluster which included parthenogenetic individuals and few sexually reproducing males, which are genetically identical to the parthenogenetic individuals. However, an analysis of the population genetic structure found no differences with respect to genotypic variation, clonal diversity, and population differentiation between the sympatric parthenogenetically and the sexually reproducing populations. The results indicated that the parthenogenetic individuals cannot outcompete the sexually reproducing individuals.

\section{Introduction}

Comparing the relative success of sexual and asexual reproduction (apomixis or parthenogenesis) systems has been a major focus of population ecology for decades [1-4]. In such comparisons, it has often been recognized that the related sexual and asexual reproducing organisms have different distributional patterns. To explain this so-called "geographical parthenogenesis," researchers have proposed several nonexclusive hypotheses, which mainly describe the benefits and advantages of asexual reproduction when in competition with their related sexuals: (1) Bierzychudek [5] and Kearney [6] have suggested that the colonization success of asexuals might be mainly caused by polyploidy. (2) Niche differentiation by producing a high number of specialised genotypes [7] or (3) the production of generalists, which can occupy a broader range of environments $[8,9]$, has been proposed as mechanisms which would favour the distribution of asexuals. (4) Alternatively, asexual reproduction has been described as a very efficient way to increase the number of offspring, though at the cost of the continuous development of new genotypes. Sexual reproduction therefore pays for new genotypes with twofold costs for reproduction. (5) Finally, the loss of genetic recombination by asexual reproduction is believed to result in low long-term evolutionary potential [10], irrespective of high degrees of short-term success due to a high colonization potential.

Given the apparently overwhelming immediate advantages of asexual reproduction, it remains unclear how sex persists in the short term. This implies that the sexual ancestor should be outcompeted by the parthenogenetic modification, at least in the habitat of origin. Therefore, 


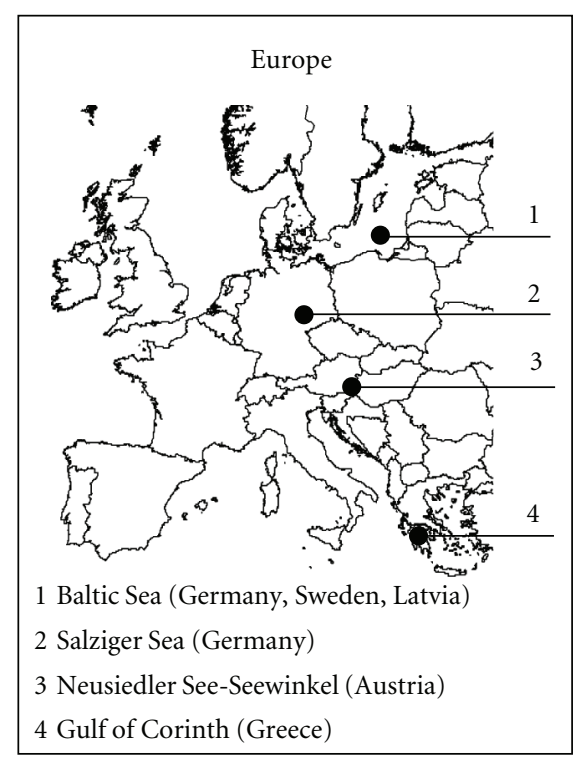

(a)

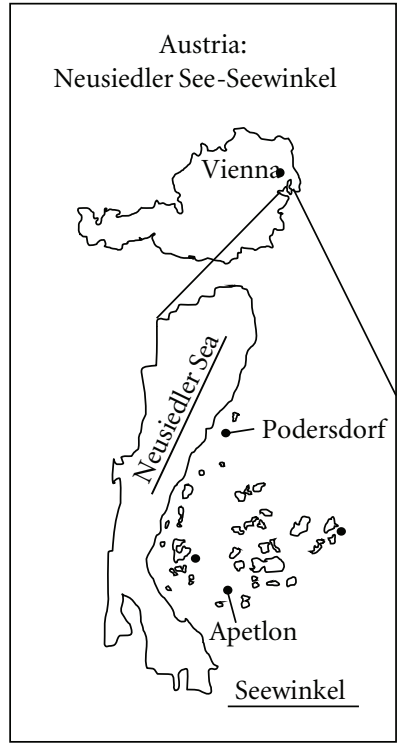

(b)

Figure 1: Geographical distribution of regions where C. canescens populations exist.

sympatric occurrences of sexual and parthenogenetic individuals should be temporal (and should exhibit a trend towards the parthenogens). In cases in which they are stable, an alternative theory about the benefits and costs of parthenogenesis is needed. Thus, conducting more studies in which asexual populations are sympatric with their sexual relatives is very important in understanding why the sexuals persist against an invasion of the asexuals.

Chara canescens (Charales, Charophyceae), a species in which both sexual and asexual (parthenogenetic) reproduction occurs, is a particularly suitable organism for such a study and provides a clear example of geographical parthenogenesis: (i) most of the occurrences of $C$. canescens only consist of parthenogenetically reproducing females (e.g., The Netherlands, France, Iberian Peninsula, and Great Britain [11]; Baltic Sea [12]; eastern Adriatic coast [13]). These parthenogenetically reproducing females are diploid with 24 chromosomes [1]. (ii) Only one sexual population in Europe with haploid females and males in separate sexes each with 12 chromosomes is known from Austria (Neusiedler See-Seewinkel $[1,14]$ ). But in the early years of the last century, Ernst [1] suggested that, in the Austrian population, both reproduction systems coexisted. Schaible et al. $[15,16]$ have also found the sympatric occurrence of sexually and parthenogenetically reproducing females in this population by means of a molecular marker and a demographic survey. These results suggested that sympatry has been present for more than a century. According to the findings of other species [17-19], such a long-term stable sympatric occurrence indicates that there may be a different kind of segregation, like a temporal segregation.

Therefore, in this study questions regarding the verification of the sympatry, as well as questions about the gene flow and the genetic diversity between populations of both reproduction systems, are addressed through a microsatellite analysis. The goal is (1) to analyse the genetic relationship and diversity of sexual and of parthenogenetic populations, in comparison with sympatric occurrences, and (2) to analyse the degree of genetic differentiation between individual populations.

\section{Materials and Methods}

2.1. Species Description. C. canescens is a dioecious member of the genus Chara. In all members of the genus Chara, the haploid gametophyte dominates the diploid sporophyte, which is reduced to the embryo in the oospores. Before oospores germinate, the meiosis takes place. Individuals of $C$. canescens cannot grow by bulbils or other vegetative forms, as has been observed in other Charophytes; they reproduce only by means of germinating oospores [12]. C. canescens is a typical brackish water species, and hence its populations occur in both ephemeral, brackish, and inland water habitats, and in permanent marine estuaries up to salinity of 20 PSU (Practical Salinity Units) [11].

2.2. Sampling Areas. A current and credible distribution of C. canescens for whole Europe is not available. For example, a recent survey of $C$. canescens in France has demonstrated the extinction in nearly all habitats which were described in literature (own observation). Therefore, our collection was limited to some unique areas. A total of 604 C. canescens individuals were sampled at 13 brackish inland water sites and eight marine sites from four geographical regions (Table 1 and Figure 1).

In the following, we give each sample region in detail.

Male and female individuals of $C$. canescens were sampled from ephemeral, brackish, and inland ponds of the Neusiedler See-Seewinkel National Park, situated close to the Austrian-Hungarian border (Table 1; Figure 1). This unique 
TABLE 1: Geographical coordinates for sampling sites of Chara canescens populations.

\begin{tabular}{|c|c|c|c|c|}
\hline Region & Name of ponds & Abbreviation & Latitude & Longitude \\
\hline \multirow[t]{8}{*}{ Baltic Sea } & Latvia 1 & BS-LE1 & $57^{\circ} 06^{\prime}$ & $23^{\circ} 23^{\prime}$ \\
\hline & Latvia 2 & BS-LE2 & $57^{\circ} 42^{\prime}$ & $24^{\circ} 17^{\prime}$ \\
\hline & Sweden & BS-SW & $56^{\circ} 32^{\prime}$ & $16^{\circ} 19^{\prime}$ \\
\hline & Germany & & & \\
\hline & Darß-Zingst & BS-DB & $54^{\circ} 22^{\prime}$ & $12^{\circ} 35^{\prime}$ \\
\hline & Greifswalder 1 & BS-GB1 & $54^{\circ} 07^{\prime}$ & $13^{\circ} 29^{\prime}$ \\
\hline & Greifswalder 2 & BS-GB2 & $54^{\circ} 18^{\prime}$ & $13^{\circ} 38^{\prime}$ \\
\hline & Salzhaff & BS-SH & $54^{\circ} 01^{\prime}$ & $11^{\circ} 31^{\prime}$ \\
\hline \multirow[t]{12}{*}{ Neusiedler See Seewinkel (Austria) } & Herrensee & NS-HS & $47^{\circ} 44^{\prime}$ & $16^{\circ} 46^{\prime}$ \\
\hline & Silbersee & NS-SI & $47^{\circ} 48^{\prime}$ & $16^{\circ} 46^{\prime}$ \\
\hline & Runde Lacke & NS-RL & $47^{\circ} 47^{\prime}$ & $16^{\circ} 47^{\prime}$ \\
\hline & Südl. Stinkersee & NS-SS & $47^{\circ} 47^{\prime}$ & $16^{\circ} 47^{\prime}$ \\
\hline & Albersee & NS-AS & $47^{\circ} 46^{\prime}$ & $16^{\circ} 46^{\prime}$ \\
\hline & Weißsee & NS-WS & $47^{\circ} 43^{\prime}$ & $16^{\circ} 49^{\prime}$ \\
\hline & Zicklacke & NS-ZL & $47^{\circ} 46^{\prime}$ & $16^{\circ} 47^{\prime}$ \\
\hline & Hottergrube & NS-HG & $47^{\circ} 46^{\prime}$ & $16^{\circ} 49^{\prime}$ \\
\hline & Neubruchlacke & NS-NL & $47^{\circ} 46^{\prime}$ & $16^{\circ} 52^{\prime}$ \\
\hline & Heidlacke & NS-HL & $47^{\circ} 47^{\prime}$ & $16^{\circ} 49^{\prime}$ \\
\hline & Krötenlacke & NS-KL & $47^{\circ} 46^{\prime}$ & $16^{\circ} 47^{\prime}$ \\
\hline & Gölser See & NS-GS & $47^{\circ} 52^{\prime}$ & $16^{\circ} 50^{\prime}$ \\
\hline Inland brackish water (Germany) & Salziger See & BI-SS & $51^{\circ} 27^{\prime}$ & $11^{\circ} 42^{\prime}$ \\
\hline Greece & Gulf of Corinth & GR-GC & $37^{\circ} 56^{\prime}$ & $22^{\circ} 53^{\prime}$ \\
\hline
\end{tabular}

region has been described in detail by Metz and Forró [20] and is characterized by a multitude of shallow, highly alkaline ponds with salinities ranging from 0.5 to 6 PSU. Seasonal evaporation of the ponds begins by the end of May. In most ponds, a dense, a monospecific stand of $C$. canescens covers the lagoon bottom from the surface down to a maximum depth of $0.5 \mathrm{~m}$, and other macrophytes are rarely observed.

From the more than 50 shallow ponds, 12 had Chara populations that were sampled for genetic analyses ("NS" population, Table 1). Male and female C. canescens could be distinguished by their sexual organs (oogonium for females and antheridia for males). Schaible et al. [15] described that in four of the ponds, Silbersee (NS-SI), Albersee (NSAS), Südlicher Stinkersee (NS-SS), and Runde Lacke (NS$\mathrm{RL}$ ), the C. canescens populations exhibited a male-to-female ratio of $\sim 1: 1$, whereas three of the ponds, Gölser See (NSGS), Heidlacke (NS-HL), and Krötenlacke (NS-KL), were populated by females only. In the remaining ponds, Weißsee (NS-WS) and Hottergrube (NS-HG), a disproportionate male-to-female ratio of $\sim 1: 100$ was observed. In three additional ponds (NS-HS, NS-NL, and NS-ZL), no sex proportion in detail was determined.

An all-female $C$. canescens population was sampled from the remains of the saline lake Salziger See, located near Halle, Germany (Table 1). This site (BI-SS) has been described in detail by Schubert et al. [21].

Other all-female populations of $C$. canescens were sampled from two marine estuarine habitats along the coasts of the Baltic and Mediterranean Seas (Table 1). These habitats are characterized by large salinity gradients (0.5-18 PSU), and the ionic composition is dominated by $\mathrm{Na}^{+}$and $\mathrm{Cl}^{-}$. In these habitats, the salinity and ionic composition of the water varies with the changing of marine and freshwater influx. In most populations, C. canescens compete for space and resources with other macrophytes.

In the five locations along the Baltic Sea coast, Salzhaff (BS-SH), Darß-Zingst estuary (BS-DB), Greifswalder estuary (BS-GB), Sweden (BS), and the Gulf of Riga (BS-LV), individuals were sampled from populations where no male plants have been found. These sites have been described in detail by Blindow and Schubert [12]. In Greece, female C. canescens were sampled from the Gulf of Corinth (GR-GC; $[13])$.

2.3. DNA Isolation. Genomic DNA was isolated from about $30 \mathrm{mg}$ of freeze-dried, powered biomass of $C$. canescens, using the DNeasy Plant Mini Kit (QIAGEN, Hilden, Germany). For cell disruption, a glass bar and a $2 \mathrm{~mL}$ reaction tube were used. This method does not significantly affect diatom cells, and thus no, or only a little, diatom DNA was extracted. The quality and quantity of DNA was determined on $1 \%$ agarose gels.

2.4. Microsatellite Analysis. The genetic differentiation between populations was assessed by analyzing four polymorph microsatellite loci specifically designed for C. canescens: ChcanA9, ChcanA19, ChcanA6, and ChcanA1 (Table 2). The microsatellite loci were identified from a C. canescens microsatellite library (prepared by the Genetic Identification Service, Chatsworth, Calif, USA), based on DNA of 


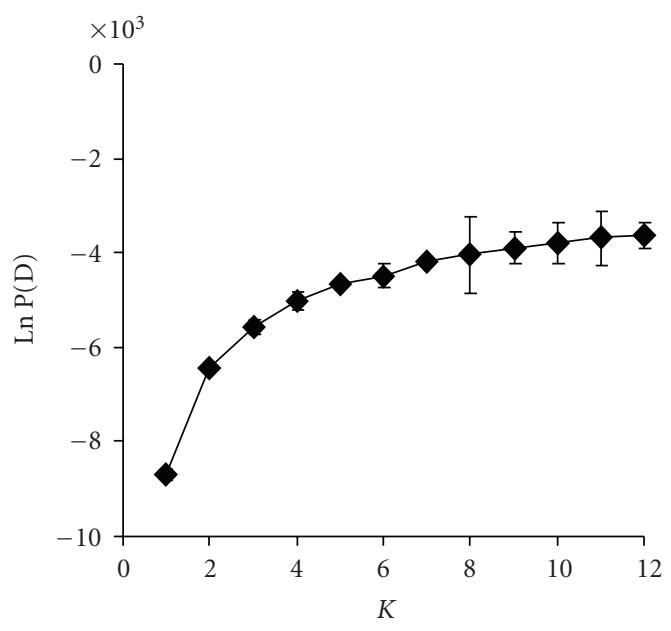

(a)

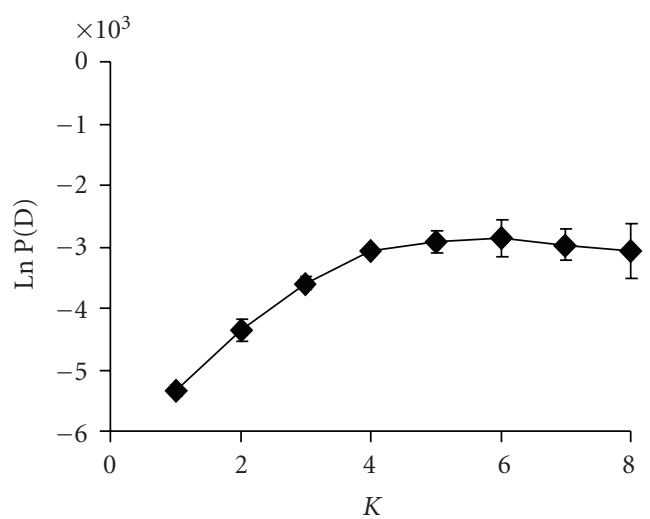

(c)

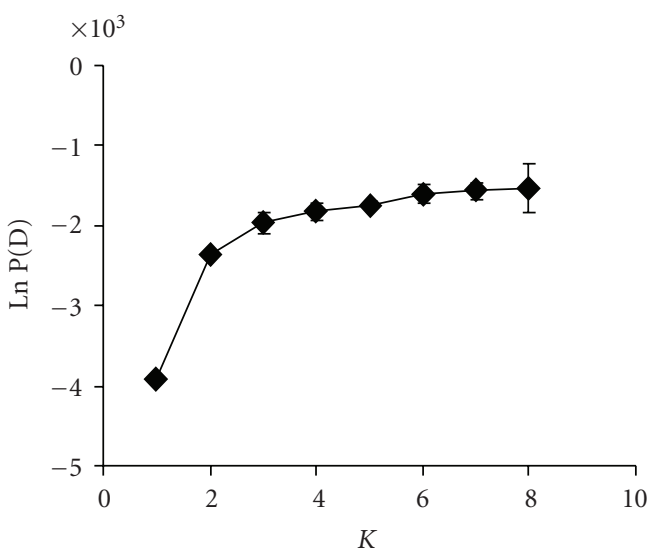

(e)

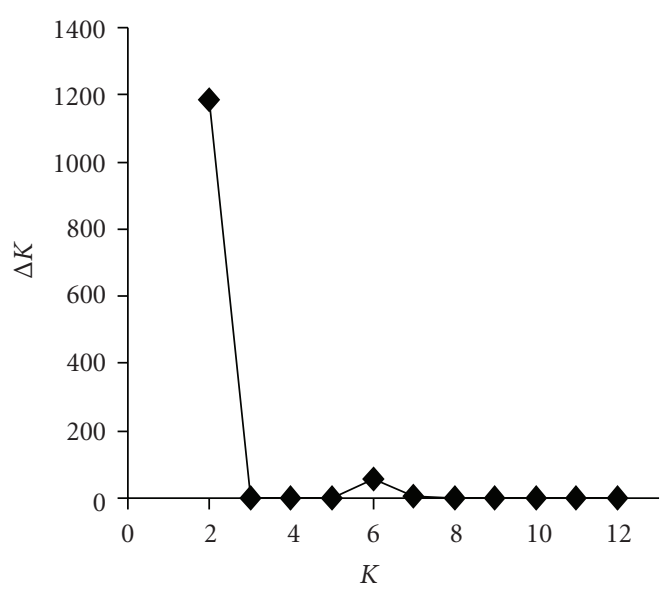

(b)

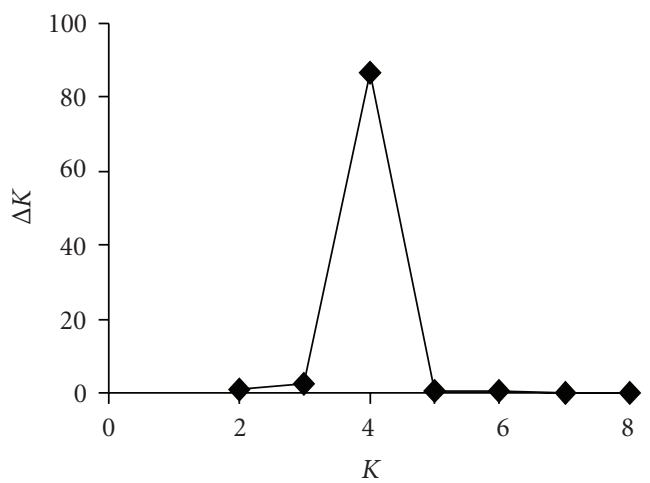

(d)

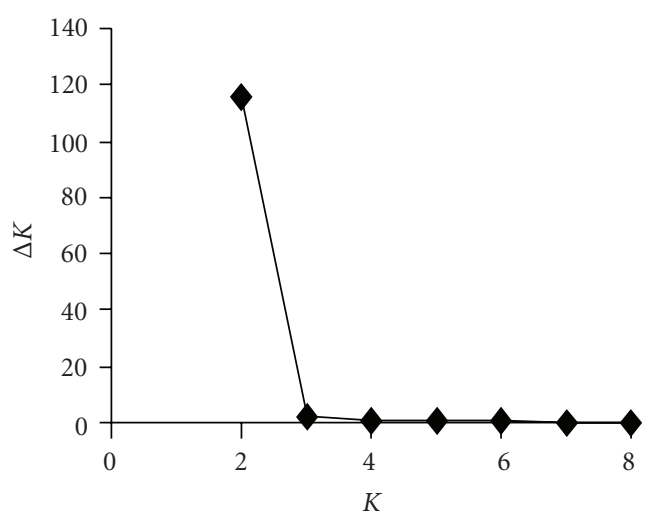

(f)

FIGURE 2: Results of Bayesian clustering: the average $\mathrm{LnP}(\mathrm{D})$ and $\Delta K$ over 5 repeats of STRUCTURE simulations. (a)-(b) LnP(D) with $k=$ $1-12, \Delta K$ with $k=2-12$ for simulation using all $C$. canescens populations; (c)-(d) $\mathrm{LnP}(\mathrm{D})$ with $\mathrm{k}=1-8, \Delta K$ with $k=2-8$ for simulation using all sexually reproducing $C$. canescens individuals of Neusiedler See-Seewinkel; (e)-(f) $\operatorname{LnP}(\mathrm{D})$ with $k=1-8, \Delta K$ with $k=2-8$ for simulation using all parthenogenetically reproducing C. canescens individuals.

parthenogenetically reproducing C. canescens oospores of a Baltic Sea population (Neuendorfer Wiek; BS-NW, $54^{\circ} 55^{\prime} \mathrm{N}$, $\left.13^{\circ} 30^{\prime} \mathrm{E}\right)$.

The PCR conditions used in the analyses were as follows: $5 \mu \mathrm{L}$ Taq PCR Master Mix (Qiagen GmbH, Hilden, Germany), $1 \mu \mathrm{L}$ forward and reverse primer each $(5 \mu \mathrm{M}), 2 \mu \mathrm{L}$ water (Qiagen GmbH, Hilden, Deutschland), and $1 \mu \mathrm{L}$ DNA (approx. $20 \mathrm{ng}$ ) in a total volume of $10 \mu \mathrm{L}$. The following PCR profile was used in the analyses: an initial denaturation for $5 \mathrm{~min}$ at $94^{\circ} \mathrm{C}, 35$ denaturation cycles for $0.5 \mathrm{~min}$ at $94^{\circ} \mathrm{C}$, $0.5 \mathrm{~min}$. of annealing at a locus-specific temperature (cf. Table 2), $0.5 \mathrm{~min}$ of elongation at $72^{\circ} \mathrm{C}$, and a final extension 


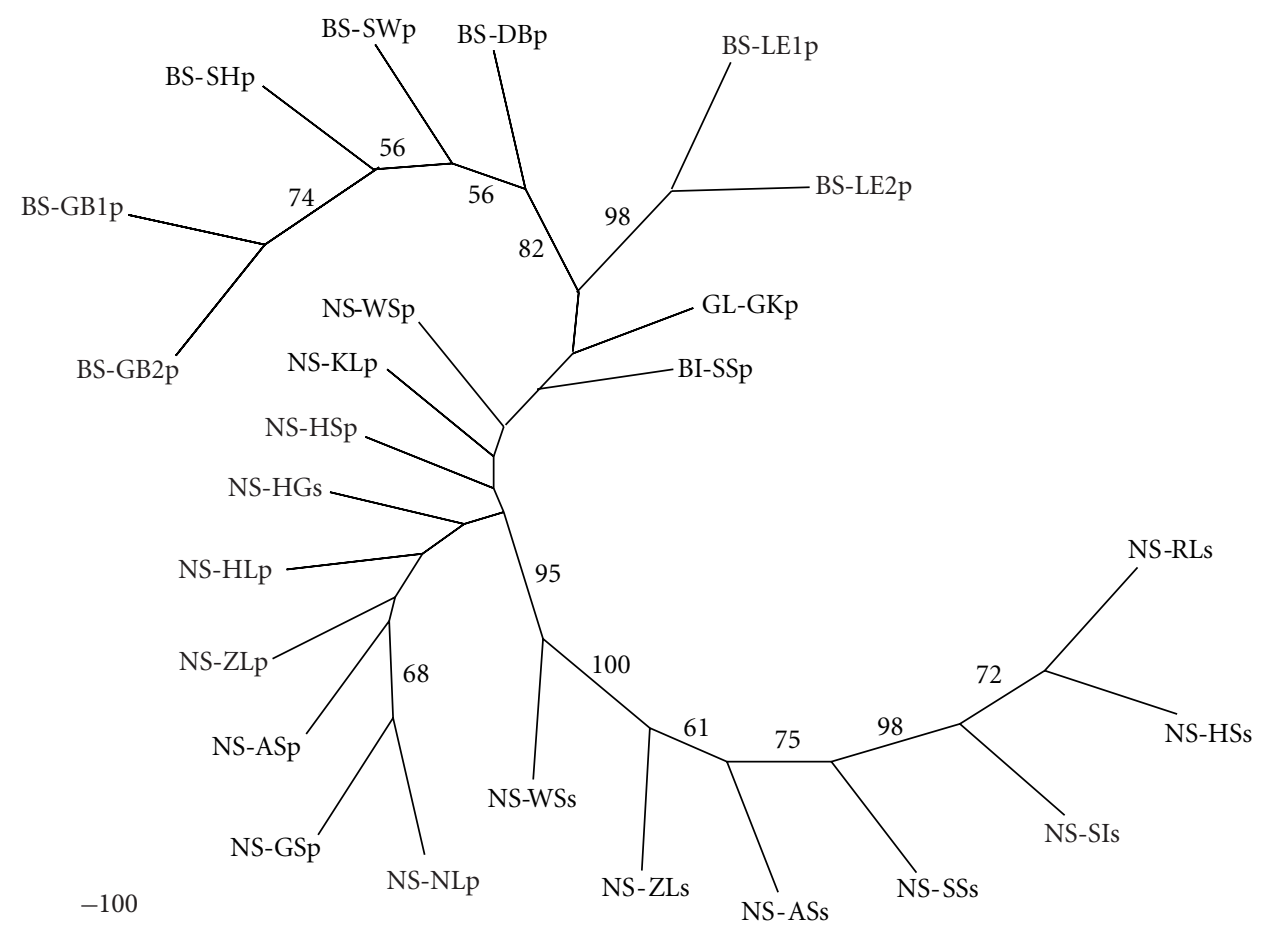

FIgure 3: Phylogeographic analysis of C. canescens populations based on Cavalli-Sforza and Edwards' [22] chord distance (DC) of allelic frequencies at four microsatellite loci. The tree was constructed using the neighbour-joining algorithm. Bootstrap values supporting separation between neighbours (based on 1000 runs) are given. Symbols and abbreviations for the populations are as in Table 1.

TABLE 2: Characterization of four microsatellite loci developed for Chara canescens; $n=604 . T_{\mathrm{a}}$ is the annealing temperature used in the analysis and $N_{\mathrm{A}}$ the is number of alleles determined.

\begin{tabular}{|c|c|c|c|c|c|c|}
\hline Locus & Repeat motif & Primer sequences $\left(5^{\prime}-3^{\prime}\right)$ & $T_{\mathrm{a}}\left({ }^{\circ} \mathrm{C}\right)$ & $N_{\mathrm{A}}$ & Size range (bp) & Accession no. \\
\hline \multirow{2}{*}{ ChcanA9 } & $(\mathrm{CA})_{\mathrm{n}}$ & F: GAGCATCCGCAGTAATCC & 55 & 14 & $147-213$ & FN430830 \\
\hline & & R: CCTCTCTGCACGTCTGTG & & & & \\
\hline \multirow{2}{*}{ ChcanA19 } & $(\mathrm{GT})_{\mathrm{n}}(\mathrm{GA})_{\mathrm{n}}$ & F: GCTTACTTCGCGCATCTAG & 60 & 17 & $127-175$ & FN430831 \\
\hline & & R: GACGAGTGCCATCTGATTC & & & & \\
\hline \multirow{2}{*}{ ChcanA6 } & $(\mathrm{CA})_{\mathrm{n}}$ & F: AAACTGGATCGGAGGTACTG & 60 & 16 & $171-237$ & AM710335 \\
\hline & & R: GCAGAGACTGTTCTTGACATG & & & & \\
\hline \multirow{2}{*}{ ChcanA1 } & $(\mathrm{AC})_{\mathrm{n}}$ & F: CACTTTGCTGCTTGCTCCAT & 60 & 16 & $191-267$ & FN430832 \\
\hline & & R: AGGAGATCAGACAGTAAGCC & & & & \\
\hline
\end{tabular}

step of $10 \mathrm{~min}$ at $72^{\circ} \mathrm{C}$. All PCR reactions were conducted in a T-gradient cycler (Biometra, Germany). Forward primers of each locus were 5' labeled with WellRED D(1-4)-PA (Proligo, France), which was designed specifically for the CEQ 2000XL DNA analysis system (Beckmann Coulter Inc.). After successful amplification, the PCR products were separated using the CEQ 2000XL DNA analysis system (Beckmann Coulter Inc.) and an internal CEQ DNA 400 size standard (Beckmann Coulter Inc.). The data were evaluated with the CEQ 8000 Series (software version 8.0.52, Beckmann Coulter Inc.) software package.

2.5. Population Structure and Differentiation Analysis. We first had to identify sexually and parthenogenetically reproducing females, because they cannot be distinguished morphologically from each other. To do this, we used two differ- ent systems, first, by means of a presence/absence marker, as described in Schaible et al. [15], and, second, by means of a model-based clustering method that allows us to use multilocus genotype data to infer population structure and to assign individuals to populations [23].

2.5.1. Presence/Absence Marker. The female individuals were considered sexual if a fragment was detected in them by means of a presence/absence marker system [15]; this specific marker was amplified with forward primer $5^{\prime}$ AACTGGATCGGAGGTACTG-3' and reverse primer $5^{\prime}$ TGGAAAGAGAAACTGCTAATA-3' . The PCR profile used for the presence/absence marker analysis was an initial denaturation for $5 \mathrm{~min}$ at $94^{\circ} \mathrm{C}, 35$ cycles of denaturation $\left(94^{\circ} \mathrm{C}\right)$, annealing $\left(55.9^{\circ} \mathrm{C}\right)$, and polymerisation $\left(72^{\circ} \mathrm{C}\right)$ each for $30 \mathrm{sec}$, followed by final extension at $72^{\circ} \mathrm{C}$ for $10 \mathrm{~min}$. 


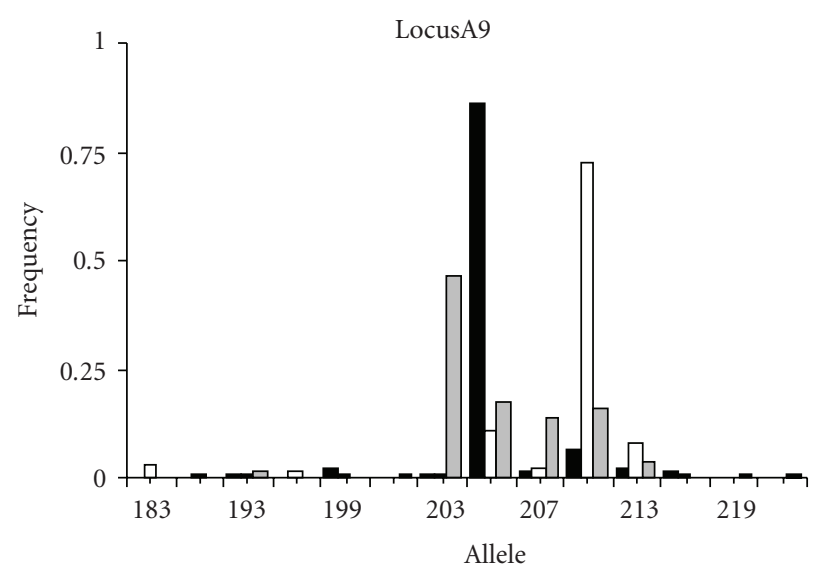

NS sex

NS parth

BS parth

(a)

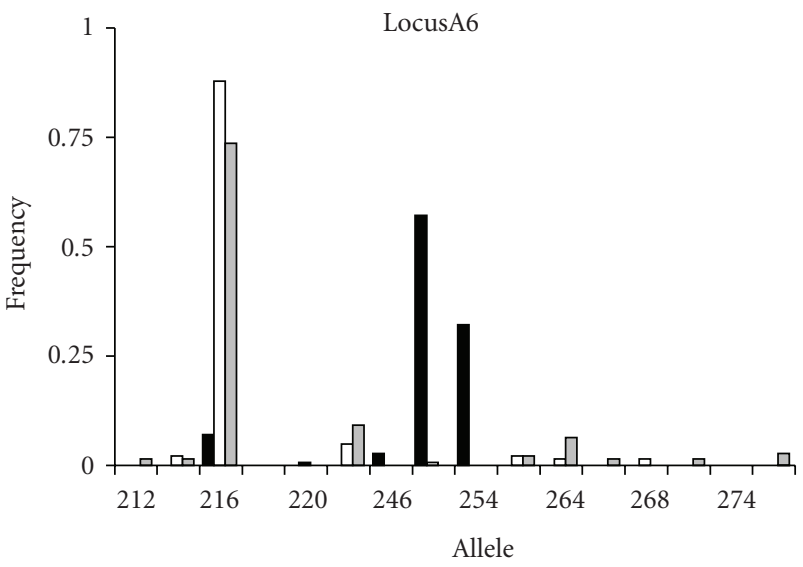

NS sex

$\square$ NS parth

BS parth

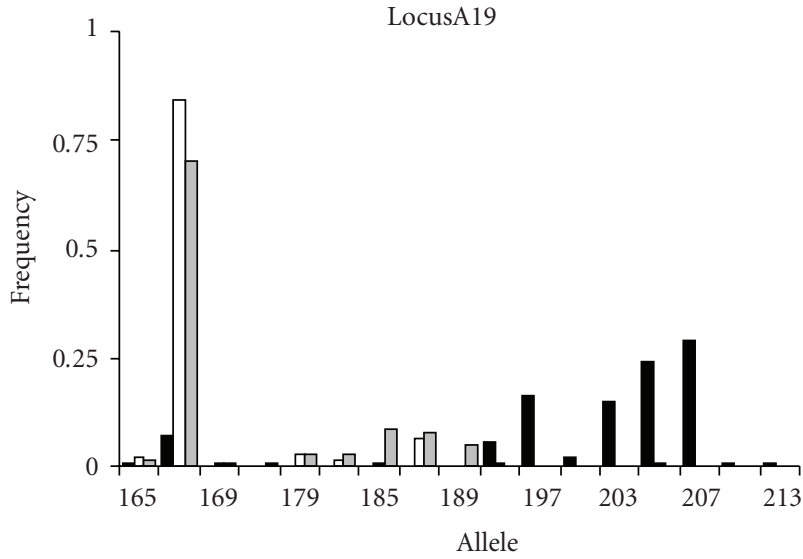

NS sex

NS parth

BS parth

(b)

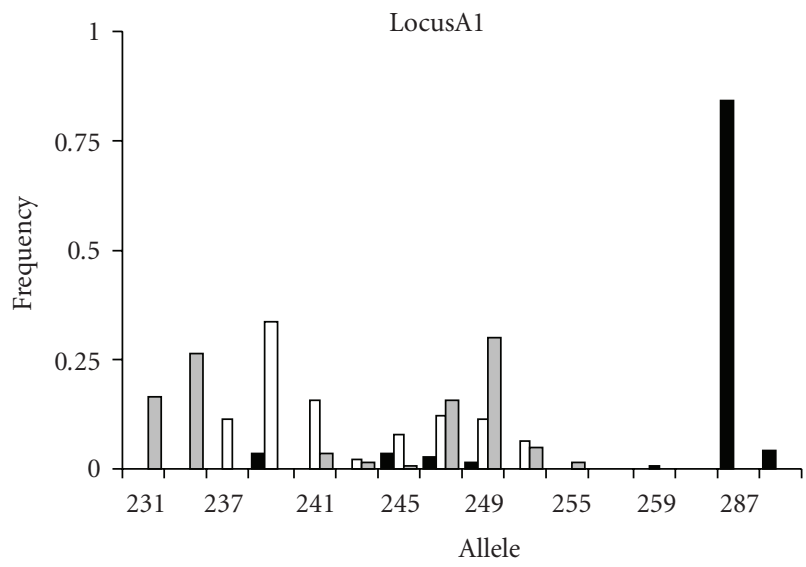

NS sex

NS parth

BS parth

(c)

(d)

Figure 4: Allelic frequencies of sexual and asexual genotypes of Chara canescens across groups defined after their reproduction mode and geographical region, and across four microsatellite loci. p, parthenogenetical reproduction; s, sexual reproduction.

If no fragments were detected after separation of the PCR products on $1 \%$ agarose gel, the individuals were considered to be parthenogenetical.

2.5.2. Bayesian Clustering Analyses. Prior to the ordination analysis of population structure, we applied a Bayesian approach of genetic mixture analysis (STRUCTURE software), which was developed by Pritchard et al. [23] and was further implemented by Falush et al. [24]. This method allows the parameters to be estimated separately from the posterior probability distribution of allele frequencies. The major parameters are $K$ the number of assumed clusters and are characterized by the matrices of allele frequencies at each locus. Parameter estimation assumes panmixia and that each locus is at HWE and is independent of the others. Nonetheless, this Bayesian approach is robust to some deviations from these assumptions of HWE [24]. Several test runs were performed to evaluate the convergence time for the simulations. This model-based program was used to infer population structure using a burning-in period of 100,000 iterations, followed by a run length of 100,000 iterations. Five independent simulations were performed to test for the consistency of the results. To determine the $K$ value first the $\operatorname{LnP}(\mathrm{D})$ and the log likelihood of the observed genotype distribution in $K$ clusters were used. The inferred $K$ is ideal when the highest $\operatorname{LnP}(\mathrm{D})$ occurs, but, because it is difficult to find the highest one, we used $\Delta K$ [25], which takes into consideration the variance of $\operatorname{LnP}(\mathrm{D})$ among repeated runs and can usually indicate the ideal $K$. 


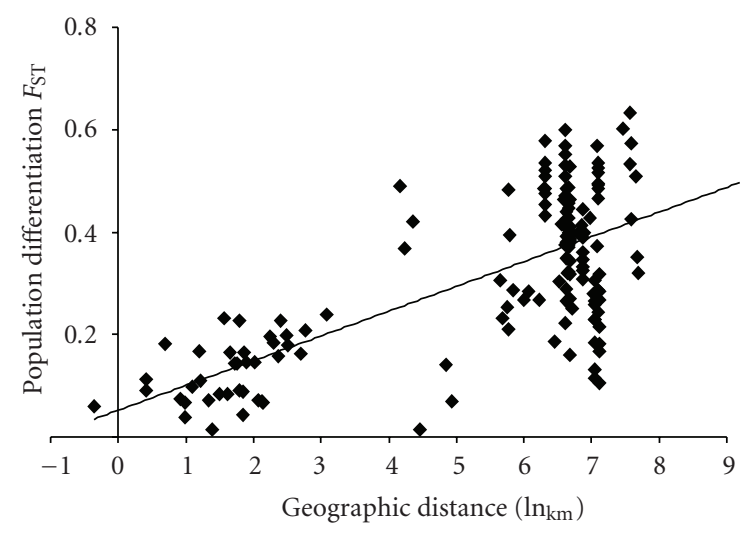

(a)

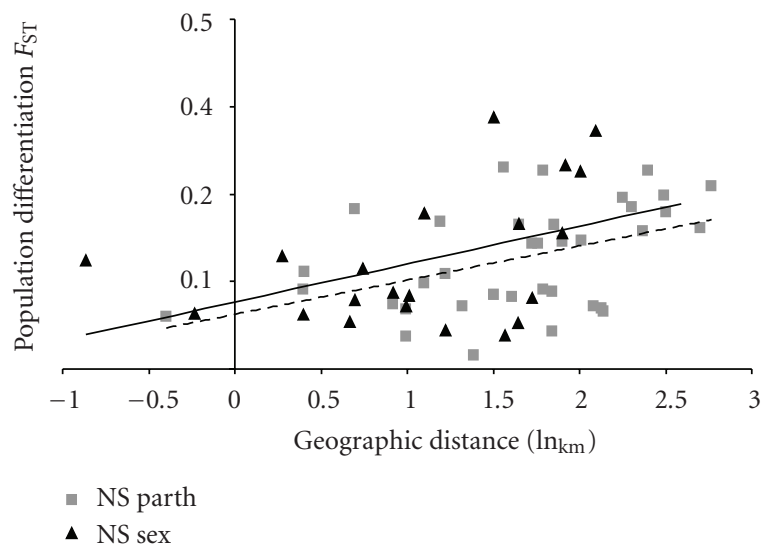

(b)

FIgURE 5: Isolation-by-distance among populations of C. canescens. Pairwise genetic differentiation quantified as Wright's $F_{\mathrm{ST}}$ that are plotted against their geographical distance in (a) all parthenogens of all populations of Baltic Sea, Greece, Salziger See and Neusiedler See-Seewinkel populations and in (b) for parthenogens and sexuals of NS populations. Estimated regression lines are shown in (a) for all parthenogenetical populations and in (b) for parthenogenetical populations (dashed line) and sexual populations (solid line).

2.6. Genetic Relationship between Populations. In order to get information about the relationship among the defined populations, a neighbor-joining tree (NJ) was constructed using Cavalli-Sforza and Edwards' [22] chord distance (DC), computed from allele frequency data. The pairwise distance matrix, the phenogram, and the bootstrap support (1,000 bootstraps) were calculated with the subprograms SEQBOOT, GENDIST, NEIGHBOR, and CONSENSE, all part of the PHYLIP 3.5 program package.

2.7. Genetic Diversity between and within Populations. As haploid sexual and diploid parthenogenetical reproducing individuals violate many of the assumptions of standard population genetic processes, such as the Hardy-Weinberg equilibrium and the Mendelian segregation, we could not estimate all commonly used parameters.

The following statistics of genetic diversity within populations were calculated per locus and were averaged over the four microsatellite loci, using GenePop 3.3 [26] and FSTAT Version 2.9.3.2 [27] software: the number of alleles per locus (A), the allele frequencies, and the nonbiased observed gene diversity, $\mathrm{H}_{\mathrm{e}}$, were computed according to Nei [28].

The extent of clonal diversity $\left(N_{G}: N\right.$ ratio $)$ in each population and group was determined by the proportion of distinguishable four-locus genotypes $\left(N_{G}\right)$, divided by the total number of samples [29]. A value of one indicates that each individual represents a unique genotype and therefore that the population exhibits maximum clonal diversity. A value approaching zero indicates that all individuals are clonal multicopies of a single genotype.

2.8. Genetic Differentiation among Populations. Levels of genetic differentiation among populations were assessed by calculating the $F_{\mathrm{ST}}$ estimator $\theta[30]$ between populations and were tested by randomizing multilocus genotypes between each pair of samples, computed by means of the program FSTAT. The pairwise $F_{\mathrm{ST}}$ were computed using FSTAT and were then tested for significance by performing 5,000 permutations of alleles or genotypes. Isolation by distance was investigated by testing for a significant correlation between $F_{\mathrm{ST}}$ and for distances between populations using the Mantel test (10,000 permutations) provided in GenePop 3.3.

\section{Results}

3.1. Characterisation of the Microsatellite. Three microsatellite-enriched libraries by hybrid selection of di- (CA and GA) and tri- (ACC) nucleotide repeats yielded 39 clones with microsatellite inserts. However, only four of these clones that rendered no or a low proportion of individuals with failing PCR reaction were selected for further analysis. Allowing for the possibility that the lack of amplifications might be due to either of the null alleles of the failed reactions, we did the following analysis for a selection of the microsatellite for C. canescens. Primer pairs were tested for 15 females of the Baltic Sea population BS-SS and 15 individuals of the Neusiedler See Seewinkel population NS-SS. At the beginning of the test phase, four primer pairs produced nonspecific multibanded products, 15 primer pairs were monomorphic, and nine primer pairs produced no product. Additionally, in four of the remaining 11 polymorphic primer pairs, the amplification partially failed with the DNA of the NS-SS individuals. Even after optimization of PCR conditions, and after testing up to three different primer pairs for each locus, only the amplification of four of the remaining seven loci was successful in more than $99 \%$ of the 604 individuals that were finally examined.

\subsection{Identification of Sexual and Parthenogenetical Individuals}

3.2.1. Presence/Absence Marker. The presence/absence marker was used to identify the reproduction system of each individual. Out of the 604 C. canescens individuals tested, 414 individuals could not be amplified by the presence/absence marker and therefore considered parthenogenetical. The remaining 190 individuals were tested positive for the 
presence/absence marker and were classified as sexually reproducing.

3.2.2. Bayesian Clustering Analyses. When we ran the STRUCTURE simulation using all 604 individuals, the $\mathrm{LnP}(\mathrm{D})$ value increased with $\mathrm{K}$ from one to 12 , but it showed an evident knee at $K=2$ (Figure 2(a)). This implied that there must be two distinctly divergent populations. The analysis of Evanno's $\Delta K$, with a sharp peak at $K=2$ (Figure 2(b)), confirms that there are separate clusters. These results showed the basic divisions between sexually and parthenogenetically reproducing individuals and correspond approximately with the prior results of the presence/absence marker. But there were, in fact, 28 samples which were classified with the presence/absence marker as sexually reproducing individuals, admixed in the cluster of the parthenogenetically reproducing individuals. It was surprising that all of the individuals, including the 12 male individuals of the NS-HG population, were found to belong to this group of samples (Table 3 ). All of the other samples were found to be females of two different populations (NS$\mathrm{ZL}$ with five samples and NS-HS with seven samples). Hence, 162 samples could be assigned to the sexual cluster and 442 individuals to the parthenogenetical cluster (Table 3).

\subsection{Identification of Sexual and Parthenogenetical Popula-} tions. Within the cluster separated by their reproduction systems Bayesian clustering without any prior information about population structure could not infer an optimal structuring into $K$ populations. However, when analyzing the data with prior information about geographical origin of the parthenogenetic populations (Figures 2(c)-2(d)), the result was nearly consistent with the natural geographical distribution: a Baltic Sea cluster (BS) with seven populations, a Greece (GL-GKp) and Salziger See cluster (BI-SS) and the Neusiedler See-Seewinkel cluster with eight populations, additionally with one Neusiedler See-Seewinkel population with both male and female individuals (NS-HGs). Within the sexual cluster (without the individuals of NS-HGs), we could detect only two separated clusters (Figures 2(e)-2(f)). But the weak resolution of the translated $\Delta K$ is more in favor of considering the populations with sexually reproducing individuals as one single population.

3.3.1. Neighbour-Joining Tree. The interrelationship was assessed by using the allele frequency of the population structure that was revealed in the combined results of both identification systems. The populations in the neighboursjoining tree did group according to their reproduction systems rather than to geographical proximity. Almost all sexually reproducing C. canescens groups (NS-RLs, -HSs, SIs, -SSs, -ASs, -ZLs, and -WSs) were separated with 95\% bootstrap support from all parthenogenetically reproducing populations (Figure 3 ). Only the NS-HGs populations with their females and males were structured within all parthenogenetically reproducing populations, completely separated from all other sexual reproducing populations. Furthermore, relationships within the groups were poorly supported, as the substructure among the clusters is very weak (Figure 3 ).

3.4. Genetic Diversity within and between Populations. Within the NSs populations, the numbers of the four locus genotypes ranged between 8 and 15, while, within the NSp populations, the numbers ranged between 3 and 22, and, within the BSp populations, the numbers ranged between 4 and 22 (Table 3). Thus, the two NS groups had fewer numbers of genotypes than the BSp group. The overall numbers of the observed genotypes of the groups were generally less than the sum of the genotypes for each group because of the presence of shared genotypes. Hence, $18 \%$ of the sexual genotypes (NSs populations) occurred two or more times, whereas $35 \%$ and $12 \%$ of the parthenogenetic genotypes of NSp and BSp populations were found at several locations. Clonal diversity $\left(N_{\mathrm{G}}: N\right)$ values were different among the populations, but similar among the groups (Table 3). Similar results were found for gene diversity $\left(H_{\mathrm{E}}\right)$. Both the clonal diversity and genetic diversity between the groups were not significantly different.

3.5. Genetic Structure and Geographic Differentiation. Four microsatellite loci provided a total of 63 alleles $(N=604)$ (Table 2). The number of alleles per locus ranged from 14 to 17 , with an overall mean for the NSs populations of 7.0 alleles per locus for sexuals and of 9.8 alleles per locus for parthenogens and a mean of 9.25 alleles per locus in parthenogenetically reproducing BS populations (Table 3 ). An analysis of allele frequency distributions reveals that a large number of alleles are not shared among reproduction groups (Figure 4): among the NSs and NSp groups, 22 unique alleles (with five alleles of frequency $\geq 0.05$ ) were observed, among the NSs and BSp groups, 40 unique alleles (with 10 alleles of frequency $\geq 0.05$ ) occurred, and among the NSp and BSp, 25 groups, unique alleles (with six alleles of frequency $\geq 0.05$ ) were detected (Figure 4 ). The special position of NSHGs within the cluster of the parthenogens may be explained by the allele frequencies, since NSHGs contain 12 alleles that are missing, at least in part, from all other sexual populations.

The genetic differentiation of the populations was determined by means of $F_{\mathrm{ST}}$ values, calculated pairwise. Most of the $F_{\mathrm{ST}}$ values were statistically significant according to a permutation test implemented in FSTAT (142 of 153 comparisons for parthenogenetically reproducing populations, and 15 of 21 comparisons for sexually reproducing populations). All single $F_{\mathrm{ST}}$ values of our analyses were plotted in Figure 5 separately for reproduction systems and geographical regions. The mean number of $F_{\mathrm{ST}}$ were similar for sexually $(0.12$; ranging between 0.04 and 0.28 ; Figure 5(b)) and parthenogenetically (0.13; ranging between 0.02 and 0.23 ; Figure $5(\mathrm{~b})$ ) population pairs from NS, while they were much higher for all other parthenogenetical populations (0.31; ranging between 0.02 and 0.63; Figure 5(a)). The mean numbers of $F_{\mathrm{ST}}$ between the NS-HGs population and all other sexually reproducing populations was quite high with 0.51 as compared to 0.09 with all other parthenogenetically reproducing populations of the NS region. 
TABle 3: Comparison of the clonal diversity $\left(N_{\mathrm{G}}: N\right)$, number of genotypes $\left(N_{\mathrm{G}}\right)$, mean number of alleles per locus $\left(N_{\mathrm{A}}\right)$, and genetic diversity $\left(H_{\mathrm{E}}\right.$, gene diversity, Nei, 1978) between sexually and parthenogenetically reproducing Chara canescens populations. P: parthenogenetical reproduction; s: sexual reproduction.

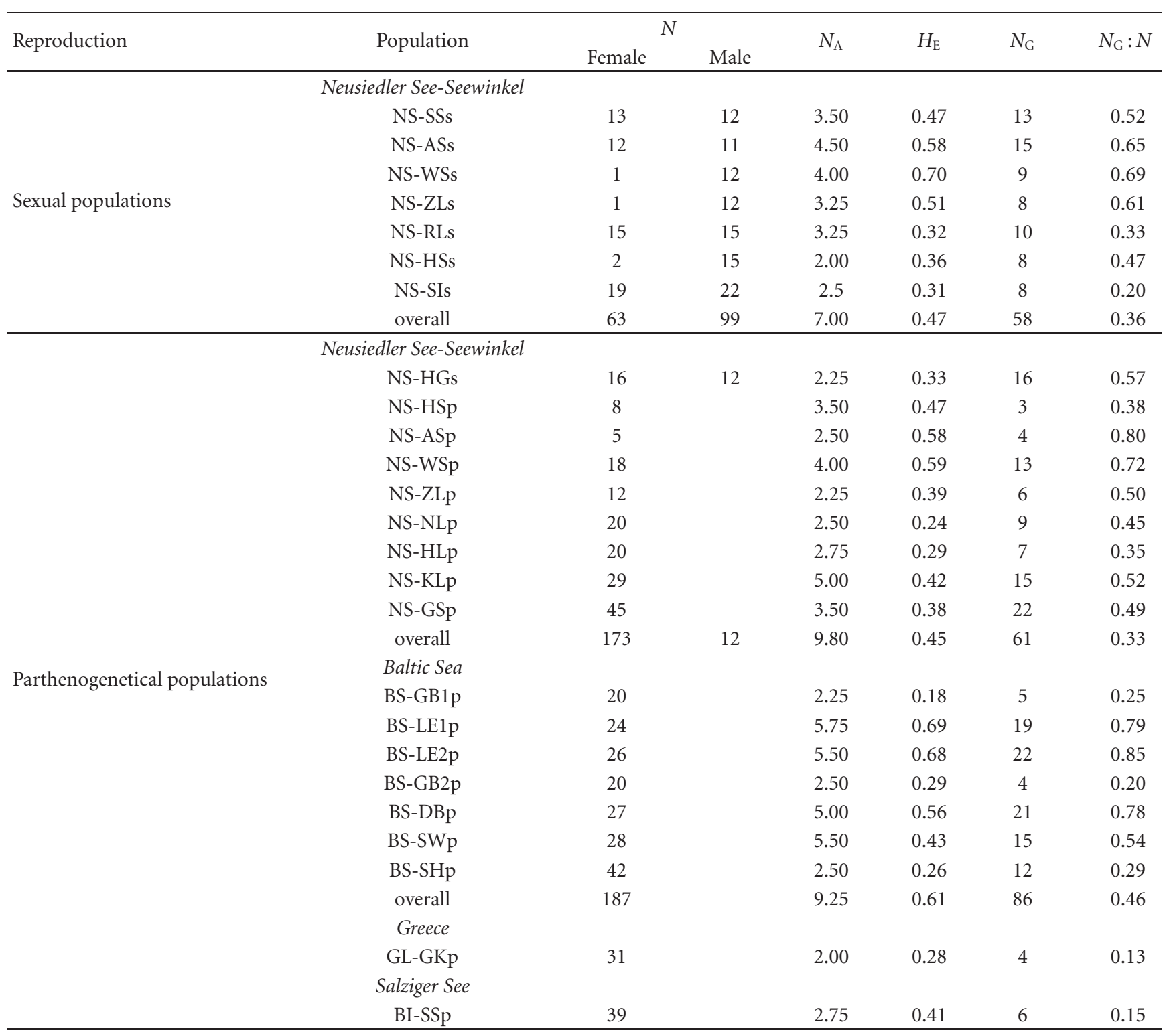

A plot of $F_{\mathrm{ST}}$ values against the geographic distances between parthenogenetically reproducing populations reveals that genetic differentiation increased linearly with the logarithm of geographical distance over the scale studied, as predicted by an isolation-by-distance model (Figure 5). The Mantel test (10,000 permutations) was highly significant $(P<.009)$ for all parthenogenetically reproducing populations (Figure 5(a)). But for parthenogens of NS alone $(P=.09)$ and sexuals of NS the Mantel test was not significant $(P=.136)$ (Figure 5(b)).

\section{Discussion}

In the present study, we investigated the geographical distribution and the genetic relatedness of sympatrical sexual and parthenogenetical populations of C. canescens. Unfortunately, obtaining a suite of polymorphic microsatellite marker for C. canescens proved to be difficult, and the evaluation of a population structure with just four loci is far from ideal. Fortunately, even with the few loci available, it proved possible to assess the genetic structure of $C$. canescens populations in a reasonably robust manner.

4.1. Parthenogenetical versus Sexual Reproduction. Careful examination of genotypic composition using the presence/absence marker at the one site and the Bayesian clustering analyses at the other site revealed that the individuals used in this study belonged to two genetically distinct clusters. These two clusters were assigned to two reproduction modes: sexually versus parthenogenetically reproducing 
individuals. Thus, the results confirmed the coexistence of sexual and parthenogenetical lineages in Neusiedler SeeSeewinkel, a phenomenon that was first observed by Ernst [1] and that was subsequently suggested by the demographic results of Schaible et al. [16]. Moreover, it seems that, for C. canescens, sexual reproduction is far less frequent than parthenogenesis, a phenomenon that has also been observed in other species with different reproduction modes $[1,6,31]$.

The Bayesian-based inference of population structure suggests that the eight sexual populations are divided into two independent genetic neighbourhoods. One group consists of a large number of males and females that were distributed throughout seven populations (Figure 3). These populations were clearly distinct from all parthenogenetically reproducing populations, as well as from the second sexually reproducing population, based on their allelic and genotypic architecture. In contrast, the second sexually reproducing group was made up of a small number of individuals that were restricted to only one site and that had an intriguingly close genetic relationship to the parthenogenetic populations. Therefore, these sexually reproducing individuals belonged to a sexual clade which may represent the original sexual ancestors of the parthenogens. The genetic similarity between the two groups implies that an ongoing transition from sexual reproduction to parthenogenesis is likely. Further investigations into the mode and the mechanism of origin of the parthenogenesis in C. canescens are required to resolve this paradox. Nevertheless, as these sexual genotypes are close to the parthenogens, we can assume that they competed with the parthenogens (for e.g., the same resources), with the parthenogens enjoying a greater advantage, as indicated by the small numbers of sexuals. In contrast the first sexually reproducing populations are genetically distinct and seem to be successful in the colonization of suitable habitat patches compared to the parthenogens. Thus, the question arises as to whether these sexuals are in direct competition with the parthenogens for resources and space.

\subsection{Genetic Diversity of the Reproduction Modes. As a first} step towards understanding the simultaneous occurrences of parthenogens and sexuals, we assessed the population genetic diversity of the two reproduction modes.

Relative to the parthenogenetical population, we anticipated that genetic recombination and diversification through sexual reproduction would lead to greater genetic diversity within the sexually reproducing population, which tends to optimise the fitness of the population in harsher environments by increasing the rate of adaptation [32, 33]. Contrary to our expectations, however, we found no genetic differences between the populations of the two reproduction systems.

For the sexually reproducing populations, similar genetic diversity with low clonal diversity was observed, compared to other sexual aquatic diploid macrophytes [34-36]. The same holds true when the results of this study are compared with those for haploid systems, such as terrestrial mosses. Since they are also gametophyte systems, haploid systems might be more appropriate for comparison purposes [3739]. At the same time, however, the habitat structure of the sexual populations, that is, small and isolated ponds, could be responsible for the lower, and yet variable, genetic diversity observed in these populations [40]. Historical information about the Neusiedler See-Seewinkel area has indicated that, as a result of the frequent changes in the hydrological regime (floating versus desiccation) that have occurred in the past, the life histories of $C$. canescens are likely to be characterised by repeated population bottlenecks, or even cycles of extinction, and thus by new colonization features that may lead to a substantially reduced degree of genetic variation within populations [40]. Unfortunately, as historical information about the genetic structure of sexual populations in Neusiedler See-Seewinkel does not exist and recent data about the genetic diversity of other geographically separated regions are not available, no reliable statement about the evolution of the genetic structure of sexuals can be made.

However, the population structure of the parthenogens in Neusiedler See-Seewinkel did reveal that they are astonishingly diverse. These results were unexpected. We have developed two hypotheses that could explain this high level of diversity. First, the genetic diversity of the parthenogenetical population may have begun with multiple successful transitions to parthenogenesis in the sympatric population $[31,41]$. As a result of the environmental heterogeneity in the Neusiedler See-Seewinkel [16], many adapted genotypes are restricted to narrow niches, which may ultimately lead to the development of heteroclonal populations. Second, high frequencies of accumulation of mutation in very ancient clones can be an important factor in increasing genetic diversity, especially in asexually reproducing organism [42, 43]. This can be of major interest in the annual C. canescens, because their distribution in the NS and the Baltic Sea had been relatively stable for the last 150 years (since they were first described by Braun [44]), producing a total of 150 generations. This long history may have led to a higher rate of mutation than the expected total genetic variance of $15 \%$ (assuming a $0.1 \%$ mutation in each generation, Smith [45]). Nevertheless, this preservation of a high degree of genetic variation favours the long-term maintenance of parthenogenetic reproduction. Therefore, the advantages associated with greater genetic diversity diminish for the sexually reproducing populations. If, in addition to their twofold advantage, these parthenogens also benefit from having a similar degree of genetic variation as that of the sexuals, it may be harder to explain the persistence of the sexuals.

4.3. Population Differentiation. Therefore, in order to understand the coexistence of the two reproduction modes, we must look at the genetic differentiation patterns within the populations of individual reproduction systems. But the estimation of the population differentiation in the Neusiedler See-Seewinkel populations showed similar degrees of population genetic differentiation in the two reproduction systems. Moreover, the high positive variability in genetic distances between populations in Neusiedler See-Seewinkel 
that was detected in both reproduction systems suggests that spatial separation plays a role in shaping the population genetic structure of both sexuals and parthenogens, even at a very short distance.

The configuration of their habitats may be responsible for this lowered genetic exchange between sexuals and parthenogens. Lakes or small ponds can be viewed as islands surrounded by a sea of inhospitable land [46]. Thus, an effective dispersal of genetic material (oospores) mediated by animals or wind seems to be hindered [47]. Another important factor that may limit dispersal between neighbouring ponds is a hydrological regime with irregular floating and desiccation events. Such events form an extremely locally heterogeneous environment in which only specific adapted genotypes can survive. Such local environmental heterogeneity in the Neusiedler See-Seewinkel populations has been previously described, for example, pond-to-pond differences in desiccation frequencies, changes in ionic composition, and rapid changes in ionic concentration $[16,20]$. Consequently, if the dispersal mediated by birds and other mechanisms is not limited, then the spreading of new individuals depends on their adaptive potential. Currently, the wider distribution of asexually reproducing populations appears to indicate that the environmental conditions favour parthenogenesis. The presence of geographical parthenogenesis is well supported by the positive significant correlation that has been found between the genetic and the geographical distances in all parthenogenetic populations (from Greece to Baltic Sea) and that has often been observed in other asexuals $[4,32,48]$. This suggests that parthenogenetical groups of C. canescens almost always have better niche adaptation, colonisation abilities, and higher ecological amplitudes than their sexual relatives $[4,6,49]$.

However, there are also specific environmental conditions in the Neusiedler See-Seewinkel which favour sexual reproduction. Schaible et al. [16] assumed that a very short vegetation period and annual desiccation seem to be beneficial for sexuals because in ponds with such conditions (NS-SSs, NS-RLs, NS-Ass, and NS-SIs) a nearly equal ratio between females and males was observed. But such specific conditions are hardly to find in estuaries of the Baltic Sea where only parthenogens occur.

4.4. Summary. For the sympatry of sexuals and parthenogens, the findings of this study demonstrated that for the sexual group which is genetically closely related to parthenogens a competition for the same habitat with higher advantage for the parthenogens is likely. In contrast, the genetically distinct sexual clade seems to steel themselves for the competition with the parthenogens, because the results of our study indicate a coexistence with different niche adaptation. Unfortunately, as new data from geographically distinct sexually reproducing population are not available, we are unable to reliably assess what potential this sexual clade has for successful competition with the parthenogens. In addition to predicting the advantages of parthenogenetic over sexual reproduction, we can also speculate in the future about how likely is it that sexuals might invade and persist in populations in which all of the individuals are reproducing parthenogenetically. Therefore the results of this study suggest many interesting future experiments, for example, to directly determine the relative fitness of populations with different reproductive modes which can vary as predicted by the population study.

\section{Acknowledgments}

This study was funded by the Deutsche Forschungsgemeinschaft (FKZSchu983/8-1/2). Thanks go to Professor A. Herzig and all members of the Limnologische Station Illmitz to the administration for the National Park Neusiedler SeeSeewinkel (Austria).

\section{References}

[1] A. Ernst, Bastardisierung als Ursache der Apogamie im Pflanzenreich, Gustav Fischer, Jena, Germany, 1918.

[2] G. Bell, The Masterpiece of Nature: The Evolution and Genetics of Sexuality, Croom Helm, London, UK, 1982.

[3] S. E. Asker and L. Jerling, Apomixis in Plants, CRC Press, London, UK, 1992.

[4] E. Hörandl, A.-C. Cosendai, and E. M. Temsch, "Understanding the geographic distributions of apomictic plants: a case for a pluralistic approach," Plant Ecology \& Diversity, vol. 1, pp. 309-320, 2008.

[5] P. Bierzychudek, "Pattern in plant parthenogenesis," in The Evolution of Sex and Its Consequences, S. C. Stearns, Ed., pp. 197-218, Birkhaeuser, Boston, Mass, USA, 1987.

[6] M. Kearney, "Hybridization, glaciation and geographical parthenogenesis," Trends in Ecology and Evolution, vol. 20, no. 9, pp. 495-502, 2005.

[7] R. C. Vrijenhoek, "Ecological differentiation among clones the frozen niche variation model," in Population Biology and Evolution, K. Woehrmann and V. Loeschcke, Eds., pp. 217232, Springer, Berlin, Germany, 1984.

[8] E. D. Parker, R. K. Selander, R. O. Hudson, and L. J. Lester, "Genetic diversity in colonizing parthenogenetic cockroaches," Evolution, vol. 31, pp. 836-842, 1977.

[9] M. Lynch, "Destabilizing hybridization, general-purpose genotypes and geographic parthenogenesis," Quarterly Review of Biology, vol. 59, no. 3, pp. 257-290, 1984.

[10] A. J. Richards, R. A. S. Smith, and M. W. Bayliss, "Apomixis in flowering plants: an overview," Philosophical Transactions of the Royal Society B, vol. 358, no. 1434, pp. 1085-1093, 2003.

[11] W. Krause, "Charales (Charophyceae)," in Süßwasserflora von Mitteleuropa, H. Ettl, G. Gärtner, H. Heynig, and D. Mollenhauer, Eds., pp. 1-202, Gustav Fischer, Jena, Germany, 1997.

[12] I. Blindow and H. Schubert, "Chara canescens Desv. et Loisel. in Loisel. 1810," in Charophytes of the Baltic Sea, H. Schubert and I. Blindow, Eds., pp. 70-81, Koeltz Scientific Books, Königstein, Germany, 2004.

[13] A. Küster, R. Schaible, and H. Schubert, "Light acclimation of photosynthesis in three charophyte species," Aquatic Botany, vol. 79, no. 2, pp. 111-204, 2004.

[14] A. Küster, R. Schaible, and H. Schubert, "Sex-specific light acclimation of Chara canescens (Charophyta)," Aquatic Botany, vol. 83, no. 2, pp. 129-140, 2005. 
[15] R. Schaible, I. Bergmann, M. Bogle, A. Schoor, and H. Schubert, "Genetic characterisation of sexually and parthenogenetically reproductive populations of Chara canescens (Charophyceae) using AFLP, rAcL, and SNP markers," Phycologia, vol. 48, no. 2, pp. 105-117, 2009.

[16] R. Schaible, I. Bergmann, and H. Schubert, "A survey of sexually reproducing female and male populations of Chara canescens (Charophyta) in the national park neusiedler seeseewinkel," Cryptogamie, Algologie, vol. 30, no. 4, pp. 279-294, 2009.

[17] F. Halkett, P. Kindlmann, M. Plantegenest, P. Sunnucks, and J. C. Simon, "Temporal differentiation and spatial coexistence of sexual and facultative asexual lineages of an aphid species at mating sites," Journal of Evolutionary Biology, vol. 19, no. 3, pp. 809-815, 2006.

[18] B. W. Spitzer and R. Haygood, "Migration load and the coexistence of ecologically similar sexuals and asexuals," American Naturalist, vol. 170, no. 4, pp. 567-572, 2007.

[19] R. F. Nespolo, C. C. Figueroa, M. Plantegenest, and J. C. Simon, "Short-term population differences in the genetic architecture of life history traits related to sexuality in an aphid species," Heredity, vol. 100, no. 4, pp. 374-381, 2008.

[20] H. Metz and L. Forró, "The chemistry and crustacean zooplankton of the Seewinkel pans: a review of recent conditions," Hydrobiologia, vol. 210, no. 1-2, pp. 25-38, 1991.

[21] H. Schubert, S. Schneider, M. Bögle, and R. Schaible, "Characeen-Wiederfunde im Bereich Teutschental Röblingen-ein Nachtrag zur Roten Liste der Algen des Landes Sachsen-Anhalt," Mitteilung zur floristischen Kartierung in Sachsen-Anhalt, vol. 10, pp. 31-34, 2005.

[22] L. L. Cavalli-Sforza and A. W. Edwards, "Phylogenetic analysis. Models and estimation procedures," American Journal of Human Genetics, vol. 19, no. 3, pp. 19-233, 1967.

[23] J. K. Pritchard, M. Stephens, and P. Donnelly, "Inference of population structure using multilocus genotype data," Genetics, vol. 155, no. 2, pp. 945-959, 2000.

[24] D. Falush, M. Stephens, and J. K. Pritchard, "Inference of population structure using multilocus genotype data: linked loci and correlated allele frequencies," Genetics, vol. 164, no. 4, pp. 1567-1587, 2003.

[25] G. Evanno, S. Regnaut, and J. Goudet, "Detecting the number of clusters of individuals using the software STRUCTURE: a simulation study," Molecular Ecology, vol. 14, no. 8, pp. 26112620, 2005.

[26] M. Raymond and F. Rousset, "GenePop (Version-1.2)population-genetics software for exact tests and ecumenicism," Journal of Heredity, vol. 86, pp. 248-249, 1995.

[27] J. Goudet, "FSTAT (Version 1.2): a computer program to calculate F-statistics," Journal of Heredity, vol. 86, pp. 485-486, 1995.

[28] M. Nei, Molecular Evolutionary Genetics, Columbia University Press, New York, NY, USA, 1987.

[29] N. C. Ellstrand and M. L. Roose, "Patterns of genotypic diversity in clonal plant species," American Journal of Botany, vol. 74, no. 1, pp. 123-131, 1987.

[30] B. S. Weir and C. C. Cockerham, "Estimating F-statistics for the analysis of population structure," Evolution, vol. 38, no. 6, pp. 1358-1370, 1984.

[31] E. Hörandl, "The complex causality of geographical parthenogenesis," New Phytologist, vol. 171, no. 3, pp. 525-538, 2006.

[32] M. R. Goddard, H. Charles, J. Godfray, and A. Burt, "Sex increases the efficacy of natural selection in experimental yeast populations," Nature, vol. 434, no. 7033, pp. 636-640, 2005.
[33] H. Olofsson and P. Lundberg, "The twofold cost of sex unfolded," Evolutionary Ecology Research, vol. 9, no. 7, pp. 1119-1129, 2007.

[34] H. J. Van Der Strate, L. Van De Zande, W. T. Stam, and J. L. Olsen, "The contribution of haploids, diploids and clones to fine-scale population structure in the seaweed Cladophoropsis membranacea (Chlorophyta)," Molecular Ecology, vol. 11, no. 3, pp. 329-345, 2002.

[35] C. R. Engel, C. Destombe, and M. Valero, "Mating system and gene flow in the red seaweed Gracilaria gracilis: effect of haploid-diploid life history and intertidal rocky shore landscape on fine-scale genetic structure," Heredity, vol. 92, no. 4, pp. 289-298, 2004.

[36] L. Chen, L. Xu, and H. Huang, "Genetic diversity and population structure in Vallisneria spinulosa (Hydrocharitaceae)," Aquatic Botany, vol. 86, no. 1, pp. 46-52, 2007.

[37] M. Van Der Velde, L. Van De Zande, and R. Bijlsma, "Genetic structure of Polytrichum formosum in relation to the breeding system as revealed by microsatellites," Journal of Evolutionary Biology, vol. 14, no. 2, pp. 288-295, 2001.

[38] D. M. Cassie, M. D. Piercey-Normore, and R. J. Belland, "Population structure of Dicranum elongatum in northeastern regions of Wapusk National Park, Manitoba, Canada," Bryologist, vol. 111, no. 2, pp. 302-309, 2008.

[39] V. Spagnuolo, S. Terracciano, and S. Giordano, "Clonal diversity and geographic structure in Pleurochaete squarrosa (Pottiaceae): different sampling scale approach," Journal of Plant Research, vol. 122, no. 2, pp. 161-170, 2009.

[40] A. Storfer, M. A. Murphy, S. F. Spear, R. Holderegger, and L. P. Waits, "Landscape genetics: where are we now?" Molecular Ecology, vol. 19, no. 17, pp. 3496-3514, 2010.

[41] J. -C. Simon, F. Delmotte, C. Rispe, and T. Crease, "Phylogenetic relationships between parthenogens and their sexual relatives: the possible routes to parthenogenesis in animals," Biological Journal of the Linnean Society, vol. 79, no. 1, pp. 151$163,2003$.

[42] E. Hörandl and O. Paun, "Patterns and sources of genetic diversity in apomictic plants: implications for evolutionary potentials," in Apomixis: Evolution, Mechanisms, and Perspectives, E. Hörandl, U. Grossniklaus, P. J. Van Dijk, and T. F. Sharbel, Eds., pp. 169-194, Koeltz, Koenigstein, Germany, 2007.

[43] E. Y. Y. Lo, S. Stefanović, and T. A. Dickinson, "Population genetic structure of diploid sexual and polyploid apomictic hawthorns (Crataegus; Rosaceae) in the Pacific Northwest," Molecular Ecology, vol. 18, no. 6, pp. 1145-1160, 2009.

[44] A. Braun, "Über Parthenogenesis bei Pflanzen," Abhandlungen der Königlichen Akademie der Wissenschaften zu Berlin, pp. 311-376, 1857.

[45] J. M. Smith, Evolutionary Genetics, Oxford University Press, Oxford, UK, 2nd edition, 1998.

[46] D. T. Bilton, J. R. Freeland, and B. Okamura, "Dispersal in freshwater invertebrates," Annual Review of Ecology and Systematics, vol. 32, pp. 159-181, 2001.

[47] P. Clausen, B. A. Nolet, A. D. Fox, and M. Klaassen, "Longdistance endozoochorous dispersal of submerged macrophyte seeds by migratory waterbirds in northern Europe-a critical review of possibilities and limitations," Acta Oecologica, vol. 23, no. 3, pp. 191-203, 2002.

[48] B. J. A. Pollux, M. D. E. Jong, A. Steegh, E. Verbruggen, J. M. Van Groenendael, and N. J. Ouborg, "Reproductive strategy, clonal structure and genetic diversity in populations of the aquatic macrophyte Sparganium emersum in river systems," Molecular Ecology, vol. 16, no. 2, pp. 313-325, 2007. 
[49] A. Doroszuk, M. W. Wojewodzic, and J. E. Kammenga, "Rapid adaptive divergence of life-history traits in response to abiotic stress within a natural population of a parthenogenetic nematode," Proceedings of the Royal Society B, vol. 273, no. 1601, pp. 2611-2618, 2006. 

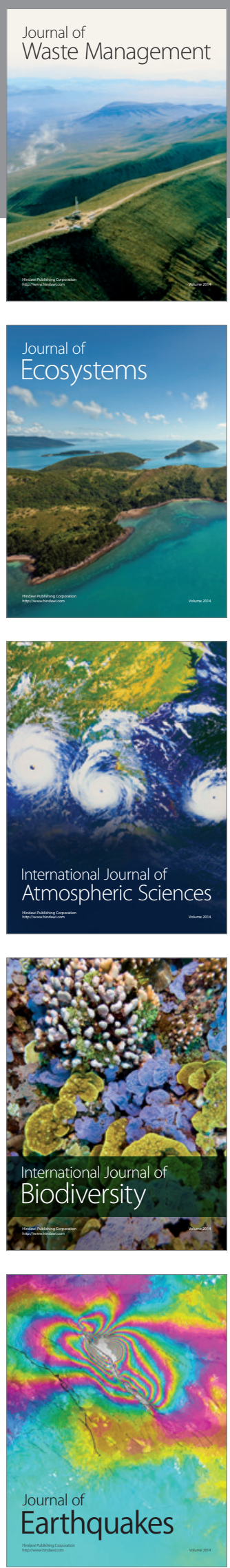
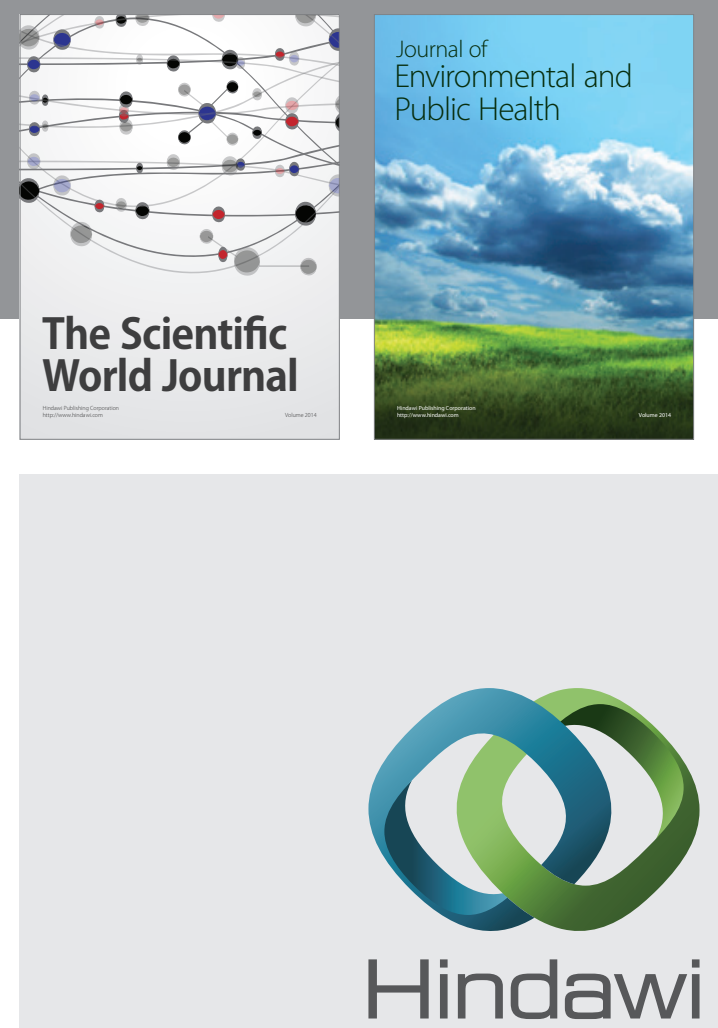

Submit your manuscripts at

http://www.hindawi.com
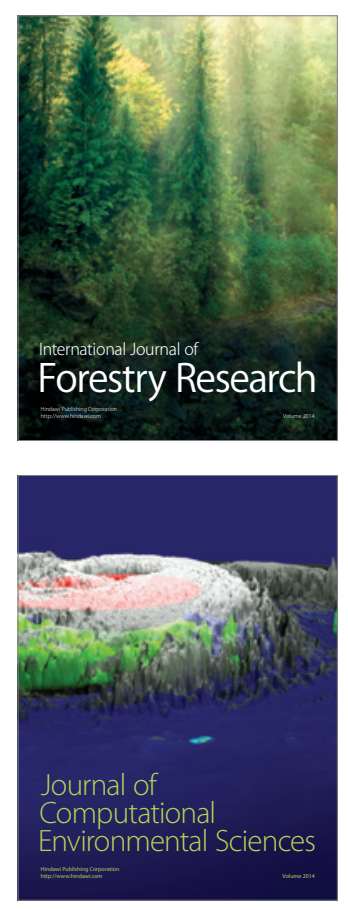
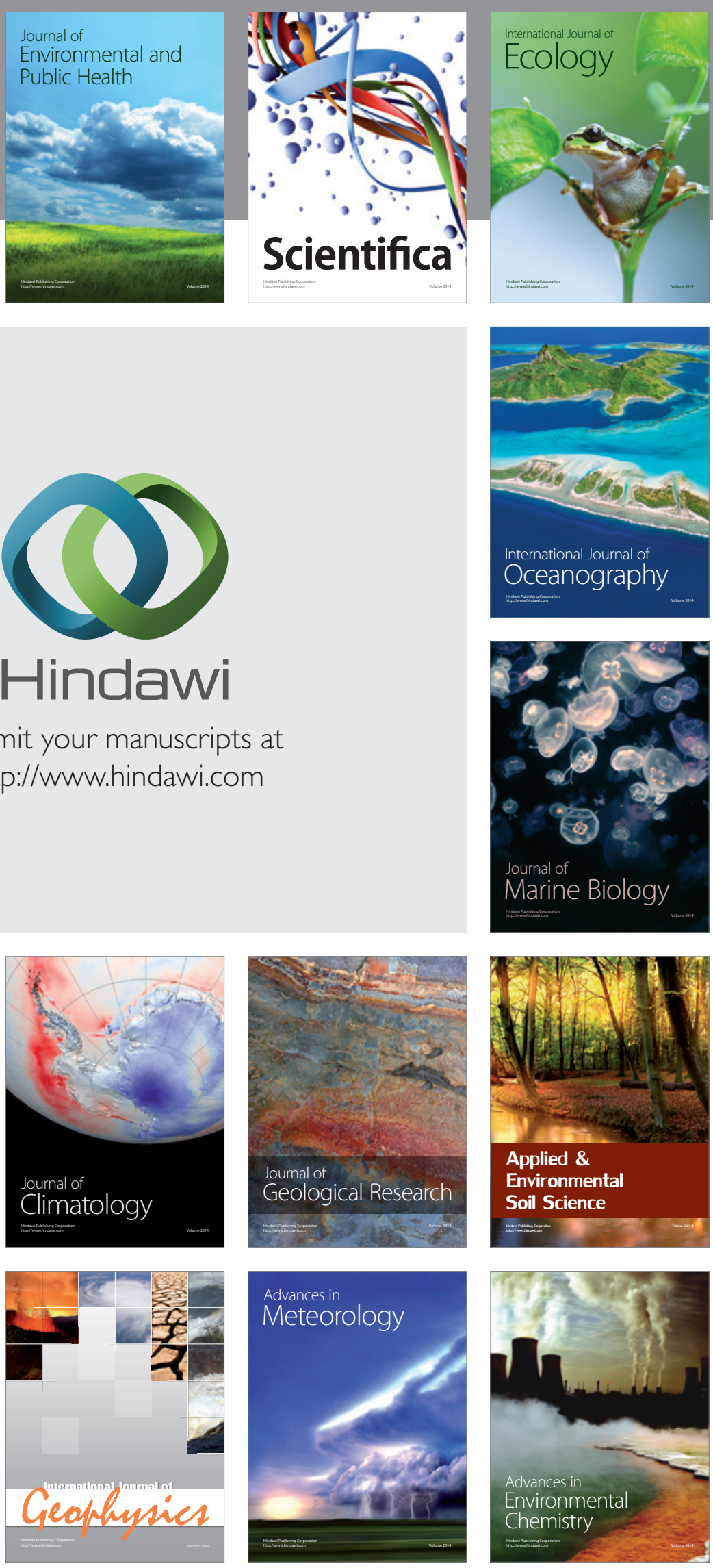